\title{
Identifikasi Variabel Berpengaruh Terhadap Jalur Evakuasi Bencana Banjir di Kecamatan Widang, Kabupaten Tuban
}

\author{
Ahmad Ikhfan Efendi dan Adjie Pamungkas \\ Jurusan Perencanaan Wilayah dan Kota, Fakultas Teknis Sipil dan Perencanaan, \\ Institut Teknologi Sepuluh Nopember (ITS) \\ Jl. Arief Rahman Hakim, Surabaya 60111 Indonesia \\ e-mail: adjie.difi@gmail.com
}

\begin{abstract}
Abstrak-Kecamatan Widang merupakan salah satu Kecamatan di Kabupaten Tuban yang paling rawan terhadap bencana banjir. Pada tahum 2008 dan 2009, hampir satu kecamatan Kecamatan Widang terdampak bencana banjir akibat dari luapan sungai Bengawan Solo. Namun sampai saat ini penyediaan jalur evakuasi masih belum optimal. Maka dari itu diperlukan jalur evakuasi yang memiliki waktu evakuasi paling optimal. Penelitian ini diawali dengan mengidentifikasi variabelvariabel yang berpengaruh dengan menggunakan content analysis. Selanjutnya, jalur evakuasi ditentukan berdasarkan variabel berpengaruh. 4 tahapan penentuan jalur evakuasi adalah menentukan kawasan terdampak banjir, menentukan lokasi evakuasi, menentukan rute evakuasi dengan menggunakan network analysis, dan menentukan jalur evakuasi.
\end{abstract}

Kata Kunci-Bencana Banjir, Kecamatan Widang, Content Analysis, Jalur Evakuasi.

\section{PENDAHULUAN}

$\mathrm{G}$ EOGRAFIS di Indonesia mempunyai kerentanan yang cukup tinggi terhadap bencana terutama banjir dan perubahan iklim. Persoalan klasik yang ada di indonesia adalah banjir di musim penghujan dan kekeringan di musim kemarau yang terjadi sepanjang tahun, sehingga muncul istilah baru untuk musim yang ada di Indonesia, yaitu musim banjir dan musim kekeringan (Kodoatie dan Sjarief, 2010) [1].

Kabupaten Tuban merupakan salah satu kawasan yang dialiri Sungai Bengawan Solo dan masuk dalam kawasan Sub DAS Bengawan Solo Hilir. Dari kawan yang dilewati Sungai Bengawan Solo, Kecamatan Widang merupakan kawasan yang paling rentan terhadap banjir karena genangan banjir yang terjadi meliputi hampir keseluruhan Kecamatan [2]. Bencana banjir di Kecamatan Widang seringkali terjadi pada setiap tahunnya, seperti yang terjadi tahun 2008 dan 2009 yang menggenangi kawasan permukiman dan persawahan di Kecamatan Widang dengan ketinggian 50-100 cm [3]. Dari 16 desa yang ada di Kecamatan Widang, hanya desa minohorejo yang aman dari banjir, sedangkan 15 desa lainnya terdampak banjir yang menggenangi persawahan dan sekitar 2.000 pemukiman warga dengan kedalaman berkisar 0, 5-1 $\mathrm{m}$ [4].

Berdasarkan Undang-Undang Nomor 24 Tahun 2007 tentang penanggulangan bencana, prioritas penanganan didasarkan pada keselamatan jiwa manusia. Oleh sebab itu, penanganan bencana banjir dilakukan dengan mendahulukan penanganan dalam penyelamatan jiwa manusia [5]. Salah satu bentuk kegiatan pengurangan korban jiwa pada saat bencana adalah dengan pengingkatan kesiapsiagaan dan salah datu bentuk kesiap siagaan adalah adanya jalur evakuasi yang dapat mempermudah arah evakuasi masyarakat ke tempat yang aman saat terjadi bencana [6].

Permasalahan mengenai pengadaan jalur evakuasi yang belum optimal menyebabkan perlunya pertimbangan yang kompleks dalam merencanakan jalur evakuasi agar tidak berdampak fatal karena tidak efektifnya jalur evakuasi bencana banjir hingga menimbulkan korban jiwa yang seharusnya dapat tertolong [7]. Kecamatan widang merupakan salah satu kecamatan diperhatikan dalam kebijakan menurut Rencana Tata Ruang Kabupaten Tuban tahun 2012 mengenai pengadaan sistem jalur dan ruang untuk evakuasi kebencanaan khususnya bencana banjir di Kabupaten Tuban dapat terpenuhi. Oleh karena itu, perlu dirumuskan dahulu variabel-variabel yang berpengaruh terhadap penentuan jalur evakuasi sebagai dasar penentuan jalur evakuasi yang mudah dipahami dan dapat digambarkan dalam peta serta sesuai dengan kondisi lingkungan dan kondisi masyarakat di Kecamatan Widang, Kabupaten Tuban.

\section{METODOLOGI PENELITIAN}

\section{A. Metode Pengumpulan Data}

Penelitian ini menggunakan teknik survei primer dan survei sekunder untuk mendapatkan data. Survei primer dilakukan dengan melakukan wawancara semi struktur yang bertujuan untuk mengetahui variabel-variabel yang berpengaruh terhadap penentuan jalur evakuasi banjir kepada stakeholder terpilih yang terdiri dari kelompok pemerintahan (Badan Penanggulangan Bencana Daerah Kabupaten Tuban (P1) dan Badan Perencanaan dan Pembangunan Daerah Kabupaten Tuban (P2)) kelompok Swasta (Kelompok Usaha Tani (S1)), dan kelompok masyarakat (Akademisi Kebencanaan ITS (M1) dan Toko Masyarakat di Kecamatan Widang (M2)). Sedangkan survei sekunder dilakukan dengan survei instansional untuk memperoleh gambaran umum wilayah dan gambaran bahaya banjir di Kabupaten Tuban khususnya di Kecamatan Widang.

\section{B. Metode Analisis}

Identifikasi variabel-variabel yang berpengaruh terhadap 
penentuan jalur evakuasi bencana banjir di Kecamatan Widang dengan menggunakan teknik analisis isi (content analysis). Content Analysis adalah analisis yang mengandalkan kodekode yang ditemukan dalam suatu teks perekaman data selama wawancara yang dilakukan dengan narasumber penelitian dengan sifat eksploratif [8]. Teknik analisa ini diawali dengan melakukan kajian pustaka terkait variabel penentuan jalur evakuasi yang terdiri dari variabel kedalaman genangan, luas genangan, lama genangan, jumlah laintai bangunan, kapasitas bangunan, fungsi bangunan, kondisi perkerasan jalan, lebar jalan, daya tampung jalan, waktu tempuh, dan jarak menuju lokasi evakuasi, serta hierarki jalan. Kemudian variabelvariabel tersebut ditanyakan kepada para stakeholders.

Hasil eksplorasi wawancara kemudian diubah bentuk menjadi transkrip wawancara yang akan menjadi dasar untuk proses pengodean. Proses pengodean dilakukan dengan mencermati pernyataan-pernyataan yang ada dalam transkirp sehingga dapat merepresentasikan suatu makna yang dapat menjawab pertanyaan penelitian lalu dirangkum dengan melihat frekuensi dengan ciri tertentu dari objek sehingga frekuensi unit tersebut dapat mengindikasikan hal yang sama dan dapat diklasifikasikan pengaruhnya. Setelah itu dapat ditarik kesimpulan yang merupakan variabel yang berpengaruh terhadap penentuan jalur evakuasi bencana banjir di Kecmatan Widang.

\section{HASIL DAN PEMBAHASAN}

Berdasarkan hasil tinjauan pustaka mengenai variabel penentuan jalur evakuasi bencana banjir secara umum, ada 12 variabel digunakan sebagai input proses analisis dan terbagi dalam 2 indikator yaitu, Lokasi Evakuasi dan Rute Evakuasi.

\section{A. Hasil Identifikasi Varieabel Lokasi Evakuasi}

Penentuan variabel-variabel berpengaruh terhadap penentuan jalur evakuasi bencana banjir di Kecamatan Widang dilakukan dengan teknik analisis Content Analysis. Proses analisis ini diawali dengan melakukan pengeodean dan penyederhanaan data transkrip wawancara pada setiap stakeholder. Berikut contoh penemuan kode dalam transkrip wawancara.

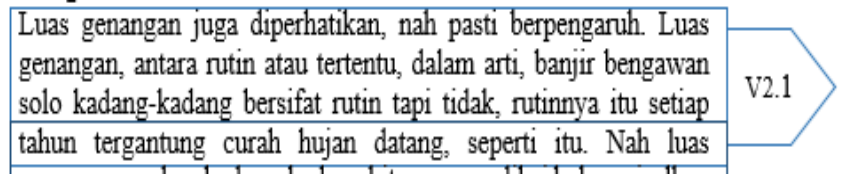

Gambar 1. Kutipan Temuan Kode pada Stakeholder 1 (P1) Transkrip 1

Berdasarkan kutipan diatas, diketahui bahwa terdapat unit analisa yang diutarakan oleh stakeholder 1 (P1) yang mengindikasikan makna bahwa variabel luas genangan (V2) mempengaruhi penentuan jalur evakuasi dengan melihat bahwa tujuan jalur evakuasi adalah menuju lokasi yang aman. Indikasi tersebut menyimpulkan bahwa stakeholder 1 menganggap variabel lama genangan berpengaruh. Proses pengodean membantu untuk memahami makna unit analisa untuk menemukan indikasi pengaruh suatu variabel. Berikut akumulasi hasil pengodean terhadap transkrip wawancara pada seluruh stakeholder.

Tabel 1.

Frekuensi Konfirmasi Stakeholder setiap Variabel Lokasi Evakuasi

\begin{tabular}{lcc}
\hline \multicolumn{1}{c}{ Variabel } & \multicolumn{2}{c}{ Jumlah Stakeholder } \\
& $\begin{array}{c}\text { Konfirmasi } \\
\text { Berpengaruh }\end{array}$ & $\begin{array}{c}\text { Konfirmasi } \\
\text { tidak } \\
\text { Berpengaruh }\end{array}$ \\
\hline Kedalaman Genangan & 5 & 0 \\
Luas Genangan & 5 & 0 \\
Lama Genangan & 5 & 0 \\
Jumlah Lantai Bangunan & 5 & 0 \\
Kapasitas Bangunan & 5 & 0 \\
Fungsi Bangunan & 4 & 1 \\
\hline \hline
\end{tabular}

Sumber: Hasil Analisis, 2016

Dari tabel diatas dapt diketahui bahwa 6 variabel yang mempengaruhi lokasi evakuasi variabel fungsi bangunann mendapat 1 konfirmasi tidak berpengaruh dari salah satu stakeholder, stakeholder tersebut adalah dari pihak Tokoh Masyarakat (M2). Stakeholder $V$ menyatakan bahwa fungsi bangunan tidak beroengaruh karena mereka lebih memilih rumah saudara dijadikan sebagai lokasi evakuasi daripada lokasi yang disediakan oleh pihak terkait.

\section{B. Hasil identifikasi variabel rute evakuasi}

Berdasarkan jumlah frekuensi konfirmasi stakeholder dapat terlihat terjadi kecenderungan indikasi pengaruh suatu variabel. Berikut contoh penemuan kode dalam transkrip wawancara.

\begin{tabular}{ll|l|}
\hline Ml : ya tentunya yang bagus, kalo jalanya rusak pas banjir kan \\
sulit lewatnya gak mungkin kan buat jalan baru, pakai aja yang & V9.1 \\
\hline sudah ada yang sering digunakan disana.
\end{tabular}

Gambar 2. Kutipan Temuan Kode pada Stakeholder 4 (M1) Transkrip 1

Berdasarkan kutipan diatas, diketahui bahwa terdapat unit analisa yang diutarakan oleh stakeholder IV (M1) yang mengindikasikan makna bahwa variabel kondisi perkerasan jalan (V9) mempengaruhi penentuan jalur evakuasi dengan melihat bahwa tujuan jalur evakuasi adalah menghindari jalanjalan dengan perkerasan yang tidak mudah rusak jika terjadi banjir. Indikasi tersebut menyimpulkan bahwa stakeholder $1 \mathrm{~V}$ menganggap variabel kondisi perkerasan jalan berpengaruh. Proses pengodean membantu untuk memahami makna unit analisa untuk menemukan indikasi pengaruh suatu variabel. Berikut akumulasi hasil pengodean terhadap transkrip wawancara pada seluruh stakeholder.

Tabel 2.

Frekuensi Konfirmasi Stakeholder setiap Variabel Rute Evakuasi

\begin{tabular}{lcc}
\hline \multicolumn{1}{c}{ Variabel } & \multicolumn{2}{c}{ Jumlah Stakeholder } \\
& $\begin{array}{c}\text { Konfirmasi } \\
\text { Berpengaruh }\end{array}$ & $\begin{array}{c}\text { Konfirmasi } \\
\text { tidak } \\
\text { Berpengaruh }\end{array}$ \\
\hline Hirarki Jalan & 5 & 0 \\
Kondisi Perkerasan Jalan & 5 & 0 \\
Daya Tampung Jalan & 5 & 0 \\
Lebar Jalan & 5 & 0 \\
Waktu Tempuh & 5 & 0 \\
Jarak Menuju Lokasi & 5 & 0 \\
\hline \hline Sumber: Hasil Analisis, 2016 & &
\end{tabular}


Dari tabel diatas dapt diketahui bahwa 6 variabel yang mempengaruhi lokasi evakuasi variabel fungsi bangunann mendapat 1 konfirmasi tidak berpengaruh dari salah satu stakeholder, stakeholder tersebut adalah dari pihak Tokoh Masyarakat (M2). Stakeholder V menyatakan bahwa fungsi bangunan tidak beroengaruh karena mereka lebih memilih rumah saudara dijadikan sebagai lokasi evakuasi daripada lokasi yang disediakan oleh pihak terkait.

\section{Hasil Indentifikasi Variabel Usulan Dari Stakeholer}

Proses pengodean membantu untuk memahami makna unit analisa untuk menemukan indikasi pengaruh suatu variable dan menemukan variabel usulan dari stakeholder. Berikut merupakan penemuan variabel usulan dari hasil pengkodean :

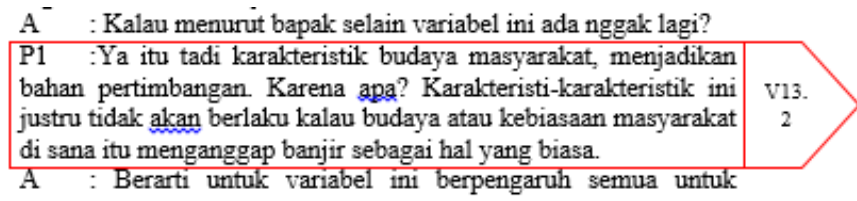

Gambar 3. Kutipan Temuan Kode pada Stakeholder 1 (P1) Transkrip 1

Berdasarkan kutipan diatas, diketahui bahwa terdapat unit analisa yang diutarakan oleh stakeholder 1 (P1) yang mengindikasikan makna bahwa variabel karakteristik budaya masyarakat mempengaruhi penentuan jalur evakuasi dengan melihat bahwa jika budaya masyarakat terbiasa dengan banjir maka tidak perlu ada jalur evakuasi. Indikasi tersebut menyimpulkan bahwa stakeholder 1 menganggap variabel karakteristik budaya masyarakat berpengaruh. Berikut akumulasi hasil pengodean terhadap transkrip wawancara pada seluruh stakeholder.

Tabel 3.

Frekuensi Konfirmasi Usulan Variabel setiap Stakeholder

\begin{tabular}{cccccc}
\hline Variabel & \multicolumn{5}{c}{ Stakeholder } \\
& P1 & P2 & S1 & M1 & M2 \\
\hline Karakteristik Budaya & 1 & 0 & 0 & 0 & 0 \\
$\begin{array}{c}\text { Masyarakat } \\
\text { Kecepatan Kenaikan } \\
\text { Permukaan Air }\end{array}$ & 0 & 1 & 0 & 0 & 0 \\
Saluran Pembuangan Air & 0 & 0 & 1 & 0 & 0 \\
\hline \hline Sumber: Hasil Analisis, 2016 &
\end{tabular}

Dari hasil tabel diatas diketahui bahwa hasil pengkodean terdapat unit analisa yang diutarakan oleh seluruh stakeholder mengusulkan 3 variabel tambahan kedalam variabel berpengaruh terhadap penentuan jalur evakuasi bencana banjir di Kecamatan Widang.

\section{Hasil Pemahaman Data}

Dalam content analysis langkah terakhir adalah proses narrating (penarasian). Tahap ini akan dilakukan analisis untuk menghasilkan jawaban dari pernyataan narasumber untuk penelitan, yaitu variabel-variabel yang berpengaruh terhadap penentuan jalur evakuasi bencana banjir di Kecamatan Widang. Hasil dari pemahaman tersebut akan mengambarkan signifikasi suatu pengaruh dari suatu variabel. Selanjutnya hasil tersebut dikombinasikan dengan teori serta kondisi lapangan di wilayah penelitian. Berikut merupakan contoh kutipan dalam transkrip terkait elemen percakapan.

Tabel 4.

Frekuensi Unit Analisis tiap Variabel dengan Maksud yang Sama pada Seluruh Stakeholder dan Frekuensi KonfirmasiStakeholder tiap Variabel

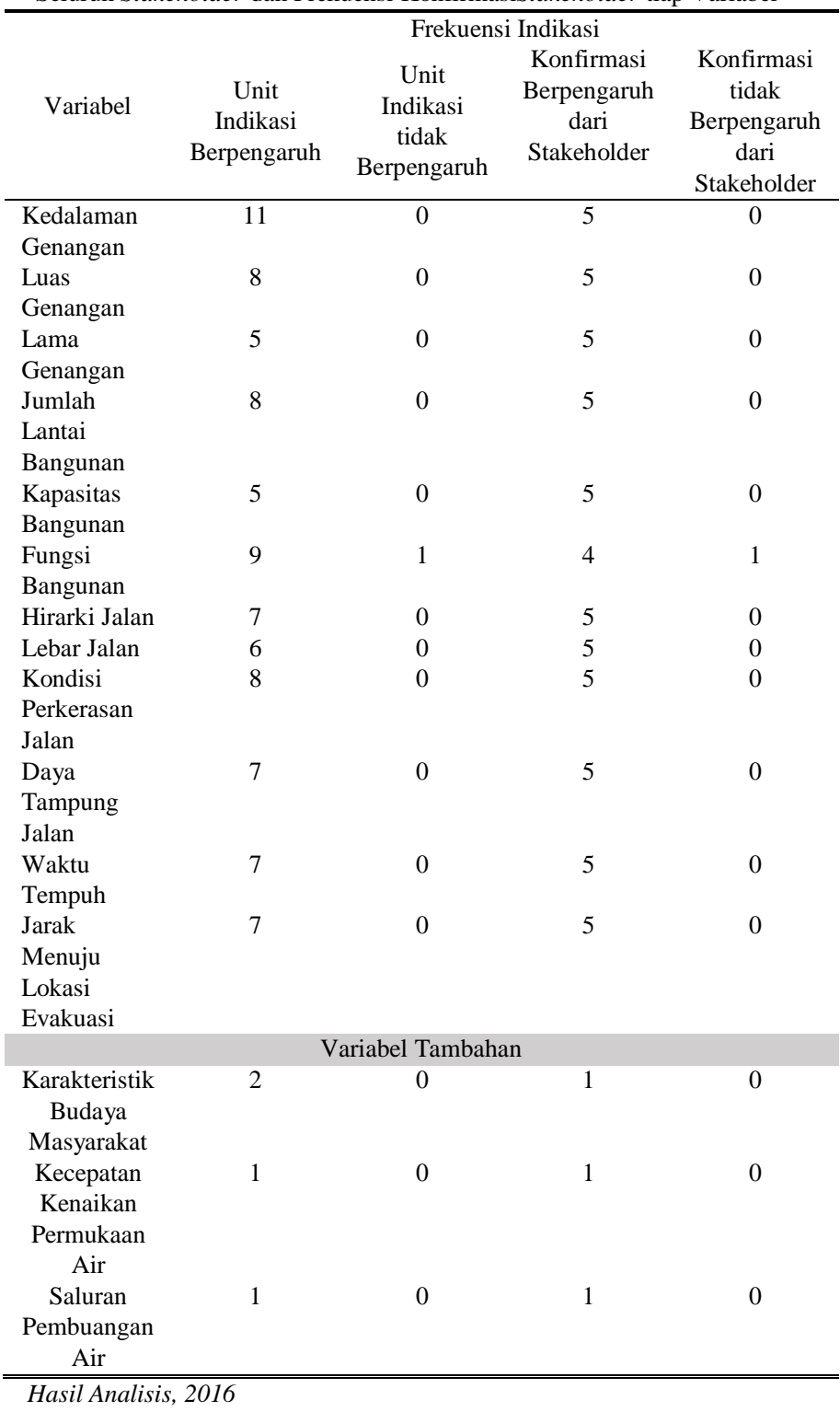

Berdasarkan tabel diatas, diketahui bahwa terdapat 12 variabel yang telah dikonfirmasi bahwa berpengaruh, namun 1 variabel yaitu hirarki jalan yang di analisis dengan kombinasi kondisi lapangan dinyatakan dihilangkan atau direduksi karena tidak sesuai dengan kondisi lapangan di Kecamatan Widang.

Sedangkan 3 variabel usulan dinyatakan tidak berpengaruh karena tidak sesuai dengan teori dan kondisi lapangan di Kecamatan Widang. Variabel karateristik masyarakat dihilangkan karena bertentangan dengan salah satu tujuan UU No. 24 Tahun 2007 tentang penanggulangan bencana. Variabel kecepatan kenaikan muka air yang tidak terlalu berpengaruh karena lebih bersifat sebagai peringatan dini menurut penelitian Japan International Cooperation Agency (JICA) [9]. Dan variabel saluran pembuangan air lebih bersifat mitigasi 
struktural atau pembangunan fisik dan tidak terlalu berpengaruh atau memiliki pengaruh kecil terhadap penentuan jalur evakuasi sehingga dapat dikatakan bahwa pengaruh variabel saluran pembuangan air tidak signifikan.

Berdasarkan hal tersebut maka variabel lain yang telah dikonfirmasi bahwa berpengaruh terhadap penentuan jalur evakuasi bencana banjir di Kecamatan Widang. Sehingga variabel yang berpengaruh terhadap penentuan jalur evakuasi yaitu luas genangan, lama genangan, kedalaman genangan, fungsi bangunan, jumlah lantai bangunan, kapasitas bangunan, lebar jalan, kondisi perkerasan jalan, daya tampung jalan, waktu tempuh, jarak menuju lokasi evakuasi.

\section{KESIMPULAN}

Berdasarkan hasil analisa dan pembahasan yang telah dilakukan pada penelitian ini, maka dapat disimpulkan bahwa:

1) Variabel yang berpengaruh terhadap lokasi evakuasi dalam penentuan jalur evakuasi di Kecamatan Widang yaitu variabel luas genangan, lama genangan, kedalaman genangan, fungsi bangunan, jumlah lantai bangunan, kapasitas bangunan,

2) Variabel yang berpengaruh terhadap rute evakuasi yaitu lebar jalan, kondisi perkerasan jalan, daya tampung jalan, waktu tempuh, jarak menuju lsi evakuasi.

3) Penentuan variabel-variabel yang berpengaruh menjadi dasar dalam penentuan jalur evakuasi bencana banjir di Kecamatan Widang, Kabupaten Tuban.

\section{DAFTAR PUSTAKA}

[1] Koedoatie, Robert J dan Sjarief, Roestam. 2010. Tata Ruang Air. ANDI. Yogyakarta.

[2] Badan Perencanaan dan Pembangunan Daerah Kabupaten Tuban. 2012. Rencana Tata Ruang Wilayah Tuban Tahun 2012-2032. Tuban

[3] Bakornas PB. 2008. Laporan Harian Posko Lakhar Bakornas PB. April 2008

[4] Roy. 2013. Banjir Bengawan Solo di Tuban dan Lamongan Makin Parah. Kompas Desember 2015.

[5] Undang-undang No. 24.2007. Penanggulangan Bencana. Indonesia

[6] Permana, Haryadi dkk. 2007. Pedoman Pembuatan Peta Jalur Evakuasi Bencana Tsunami. Jakarta: Kementerian Negara Riset dan Teknologi (KNRT).

[7] Dito, AH dan Adjie Pamungkas. 2015. Penentuan Variabel Dalam Optimasi Jalur Evakuasi Bencana Tsunami di Kecamatan Puger, Kabupaten Jember. Jurnal Tenik Pomits.

[8] Brungin, Burhan. 2010. Penelitian Kualitatif: Komunikasi, Ekonomi, Kebijakan Publik dan Ilmu Sosial Lainnya. Jakarta: Kencana Prenama Media Group

[9] JICA. 2010. Sistem Peringatan Dini Sebelum Kejadian Banjir Bandang Daerah Aliran Sungai Kalijompo di Kabupaten Jember. JICA 